\title{
Increasing the practice of thermal care to prevent newborn hypothermia: Implications for behavior change communication in rural Uttar Pradesh
}

Population Council

Follow this and additional works at: https://knowledgecommons.popcouncil.org/departments_sbsr-rh

Part of the Demography, Population, and Ecology Commons, Family, Life Course, and Society Commons, International Public Health Commons, Maternal and Child Health Commons, and the Public Health Education and Promotion Commons How does access to this work benefit you? Let us know!

\section{Recommended Citation}

Population Council. 2010. "Increasing the practice of thermal care to prevent newborn hypothermia: Implications for behavior change communication in rural Uttar Pradesh," Shaping Demand and Practices to Improve Family Health Outcomes in Northern India Policy Brief no. 4. New Delhi: Population Council. 


\section{Increasing the practice of thermal care to prevent newborn hypothermia: Implications for behavior change communication}

\section{Background}

The World Health Organization has recommended thermal control as one of the essential components of newborn care ${ }^{1}$. While thermal care is important for all newborns, it is especially critical for low birth-weight (LBW) or preterm infants as they are at risk of acquiring hypothermia, a potentially fatal condition where the newborn's normal body temperature falls below $36.5^{\circ} \mathrm{C}$. Studies indicate that in home deliveries, the incidence of hypothermia is particularly high, ranging between 39-49 percent ${ }^{2,3}$.

Effective thermal control for newborns involves the prevention of heat loss and the promotion of heat gain. 1 In large hospitals hypothermia is managed by keeping the newborn in an incubator; however, in resource-constrained rural areas, such services may not be available in health facilities such as PHCs, or during home deliveries. In these settings, adopting simple practices such as delaying the first bath of the newborn for 5-6 days and providing skinto-skin care (STSC) are effective practices to prevent hypothermia.

Skin-to-skin care (STSC) also known as Kangaroo Mother Care (KMC), entails continuous and prolonged skin-to-skin contact between the mother and the baby; that is, placing the naked baby firmly on the mother's bare chest in an upright position and breastfeeding the baby frequently and exclusively, or almost exclusively.

In October 2009, the Population Council conducted a formative study in rural Uttar Pradesh (UP) to assess current newborn bathing practices and the methods adopted to keep the baby warm immediately after birth; explore the beliefs that guide these customs and practices; identify the barriers and facilitating factors in adopting healthy newborn care practices, such as STSC; and identify programmatic and behavior change communication (BCC) initiatives that could accelerate the adoption of newborn care practices. The project was funded by the Bill and Melinda Gates Foundation.

\section{Methodology}

The formative study was conducted in two phases. First, a survey was conducted covering 4,754 households, 4,472 currently married women aged 15-34 years who had delivered a child in the last three years, 2,274 husbands, 2,372 mothers-in-law, 289 ASHAs, 284 AWWs, 161 ANMs, 316 local private practitioners, 251 panchayat members (including Village Health and Sanitation Committee members) and staff at 144 government health facilities (PHCs/CHCs) from 225 villages in 12 districts spread over the Western, Central and Eastern regions of UP. In the second phase, 308 in-depth interviews were conducted with family-level stakeholders (women, husbands and mothers-in-law), health care providers (ASHAs, AWWs, private practitioners and dais) and panchayat members to complement the information gathered in the quantitative survey. The qualitative study was conducted in 24 villages: eight villages each from three districts, one district from each of the three regions.

\section{Key findings}

Status: The Population Council study reveals that 52 percent of women had bathed the newborn within two hours of birth and 16

${ }^{1}$ WHO. 1994. Mother-baby Package: Implementing Safe Motherhood in Countries. Geneva: WHO.

${ }^{2}$ R. Kumar and A.K. Aggarwal. 1998. "Body Temperatures of Home-delivered Newborns in North India," Tropical Doctor, 28(3): 134-136.

${ }^{3}$ V. Kumar et al. 2009. "Neonatal Hypothermia in Low-resource Settings: A Review," Journal of Perinatology, 22: 1-12. 
Study findings show that community members and frontline health workers appreciate the need to keep the newborn warm immediately after birth, and various practices were adopted for newborn thermal care in the community. The method of thermal control most often mentioned by frontline workers (75 percent or more) was wrapping the newborn in a thick/warm cloth (Table 2). Far fewer (onethird) frontline health workers mentioned skin-to-skin contact, and less than 15 percent mentioned delaying the first bath as methods to keep the newborn warm (Table 2). Other methods of thermal care mentioned were to keep the room heated after delivery, to massage the newborn with mustard oil and to breastfeed the baby frequently.

percent had bathed the newborn within 24 hours of birth ${ }^{4}$. Only 32 percent of women had bathed the newborn one or more days after birth. In 15 percent of cases bathing was delayed for a week. More women (52 percent) from the Eastern region of UP as compared to the Western (29 percent) and Central (30 percent) regions bathed the newborn immediately after birth (Table 1).

Table 1: Time of initiation of newborn bathing reported by women (percent)

\begin{tabular}{|l|c|c|c|c|}
\hline Time of initiation after delivery & West & Central & East & UP \\
\hline Immediately & 29 & 30 & 52 & 37 \\
\hline Within 2 hrs & 24 & 11 & 9 & 15 \\
\hline Within 2-4 hrs & 8 & 12 & 11 & 10 \\
\hline Within 5-24 hrs & 7 & 8 & 4 & 6 \\
\hline After one or more days & 32 & 39 & 24 & 32 \\
\hline Total & $\mathbf{1 , 5 1 6}$ & $\mathbf{1 , 4 7 1}$ & $\mathbf{1 , 4 8 5}$ & $\mathbf{4 , 4 7 2}$ \\
\hline
\end{tabular}

Study findings show that institutional delivery has significant impact on delaying initiation of newborn bathing. More women who delivered in an institution (24 percent of 1,980 women) as compared to those who delivered at home (7 percent of 2,492 women) delayed bathing the newborn for a week ( $\mathrm{z}$ test, $\mathrm{p}<0.001$ ). Conversely, 51 percent of women who delivered in an institution as compared to 82 percent of women who delivered at home reported bathing the newborn within 24 hours.

Most frontline workers (86 percent of ASHAs, 96 percent of ANMs and 79 percent of AWWs) reported that cleaning the newborn with a dry cloth is better than bathing the newborn after birth. The major disadvantage of immediate bathing, as reported by 70-73 percent of AWWs and ASHAs, was that "the baby becomes cold". About onefourth of ASHAs (26 percent) and AWWs (23 percent) believed that the "baby can die" if bathed immediately. These findings indicate that frontline health workers are aware of the desired practice of not bathing the newborn immediately; however, they have not been successful in translating this knowledge into a practice within the community.

\footnotetext{
${ }^{4}$ D.S. Varma, M.E. Khan and A. Hazra, 2010. "Increasing the Practice of Thermal Care to Prevent Newborn Hypothermia and Increasing Postnatal Care of Mother and Newborn in Rural Uttar Pradesh: Implications for Behavior Change

Communication," in M.E. Khan, Gary Darmstadt, T. Usha Kiran and D. Ganju, eds Shaping Demand and Practices to Improve Family Health Outcomes: A Formative Study in Rural Uttar Pradesh. New Delhi: Population Council (forthcoming).
}

\section{Table 2: Methods to keep the newborn warm reported by} frontline health workers (percent)

\begin{tabular}{|l|c|c|c|}
\hline Method & ASHA & ANM & AWW \\
\hline STSC & 38 & 34 & 29 \\
\hline Wrapping baby in a warm cloth & 77 & 77 & 75 \\
\hline Keeping room heated after delivery & 15 & 23 & 24 \\
\hline Massaging baby with oil & 13 & 9 & 13 \\
\hline Delaying first bath for a few days & 6 & 12 & 4 \\
\hline Breastfeeding every 1-2 hours & 5 & 8 & 1 \\
\hline Total & 289 & 161 & 284 \\
\hline
\end{tabular}

Note: Percentages may add to more than 100 due to multiple responses.

Most mothers and mothers-in- law (93 percent and 82 percent, respectively) reported that they had covered or wrapped the baby with thick or woolen cloth to keep it warm. One woman said, "My child was wrapped in a blanket to keep it warm." Women and mothers-in-law also reported massaging the baby with mustard oil to keep the newborn warm. For example, a woman said, “...the nain did a mustard oil massage to keep the baby warm."

Skin-to-skin care (STSC): The vast majority (91 percent) of women $(\mathrm{N}=4,472)$ were not aware of STSC. Even when the STSC technique was explained to them, they said they were not aware of the method. A typical response by women was: "I do not know about keeping the baby on my skin or chest to keep it warm. My baby was wrapped in a towel to keep him warm."

Among women who were aware of STSC (9 percent; $\mathrm{N}=387$ ), the main sources of information on STSC were elder family members (35 percent), ASHAs (18 percent) and health care providers, including doctors in PHCs or private clinics (19 percent). Women also mentioned neighbors (15 percent) as a source of information on STSC. In the Eastern region, more women reported health care providers, including doctors in private clinics, as a source of information on STSC as compared to the ASHA who was more frequently identified as a source in the other regions of UP.

\section{Barriers}

Perception that an unbathed newborn is impure: The main reason for bathing a newborn immediately after birth, 
as reported by 60 percent of mothers-in-law, was to clean the child's body; 42 percent of mothers-in-law also believed that a newborn baby is "impure" and hence needs to be bathed immediately. A similar pattern of responses was observed in all the three regions.

Few frontline health workers (3-13 percent) mentioned that bathing the newborn immediately after birth is good for the newborn. Among health workers who perceived that a newborn should be bathed immediately, the reasons most commonly reported were "bathing cleans the baby" and it removes "impure blood" from the baby. One ASHA said, for example, "The baby is bathed immediately after birth because the child comes out from the stomach and is dirty with impure blood."

Misconceptions regarding the consequences of not bathing the newborn: In-depth interviews reveal that women and family members believe that if not bathed, the baby will smell, develop skin problems and the dirt on the body could cause infections. The following quotes highlight women's misconceptions regarding the consequences of not bathing the newborn immediately:

"The baby was given a bath to remove the 'rusi' [dirt and vernix] from its body. The 'rusi' cannot be removed by just cleaning with a cloth; bathing is necessary to remove it."

"If not bathed, there will be a foul smell from the baby's body. When the baby is in the mother's womb, the dirt inside the womb [paet ki gandagi] comes onto the baby's body. ..so the baby smells bad after birth...This dirt could cause skin infections if the child is not bathed."

Lack of awareness among women and frontline health workers regarding STSC: As discussed earlier, correct knowledge of STSC among women was negligible. However, an encouraging finding is that among women who were aware of STSC $(\mathrm{N}=387), 72$ percent $(\mathrm{N}=279)$ had practiced STSC with their last child. Of the 279 women who had practiced STSC, 37 percent $(\mathrm{N}=104)$ had correctly adopted the practice. This finding indicates that if women are counseled and made aware of STSC, many do adopt the practice.

Of the 108 women who were aware of STSC but had not practiced it with their last child, the main reasons for not adopting the practice were because they felt is was not necessary (66 percent) and because they were not aware of STSC at the time of their last delivery (32 percent).

Frontline health workers' lack of correct knowledge of STSC is another barrier in counseling women and their families on STSC. Only 32-36 percent of ASHAs and ANMs could correctly explain how STSC is practiced. Two-thirds of ASHAs described several inaccurate methods of practicing STSC, including 18 percent who described the method as keeping the newborn on the mother's clothed chest and covering the child with a cloth.
Facilitating factors

Contact with ASHA/ANM: Contact with the ASHA/ANM is important in promoting healthy practices. Analysis of the data shows that women who had met the ASHA/ANM during the antenatal period were significantly more likely (OR 1.43; $\mathrm{p}<0.001$ ) than those who had no contact with the ASHA/ANM to delay newborn bathing for 24 hours.

Institutional delivery and skilled birth assistance: Women who delivered in a health facility were four times more likely (OR 4.28; $\mathrm{p}<0.001$ ) to have delayed newborn bathing as compared to women who delivered at home without skilled assistance. In case of home deliveries assisted by a skilled birth attendant, women were one and a half times more likely (OR 1.53; $\mathrm{p}<0.05$ ) than those who did not have skilled assistance to delay newborn bathing. This finding highlights the importance of institutional delivery in promoting newborn thermal care and related newborn health behaviors.

Mass media exposure: Women who were exposed to the mass media were significantly more likely (OR 1.28, $\mathrm{p}<0.001$ ) than those who with no media exposure to delay newborn bathing.

Religious rituals and influence of village priests: As mentioned earlier, one-third of women had delayed newborn bathing for one day or more while about 14 percent had delayed bathing for a week. The qualitative study reveals that in some cases newborn bathing is not delayed due to health considerations but because the village pundit selects an auspicious date when the newborn is to be ritually bathed for the first time. A woman said, "The baby was bathed on the third day on the advice of the family pundit. My father-in-law called the pundit; the pundit gave us the date and time for bathing the baby." Although ritual bathing of the newborn is not extensively followed in rural UP, some families in all three regions of UP reported the practice. BCC efforts could build on this religious practice to encourage women to delay the initiation of newborn bathing.

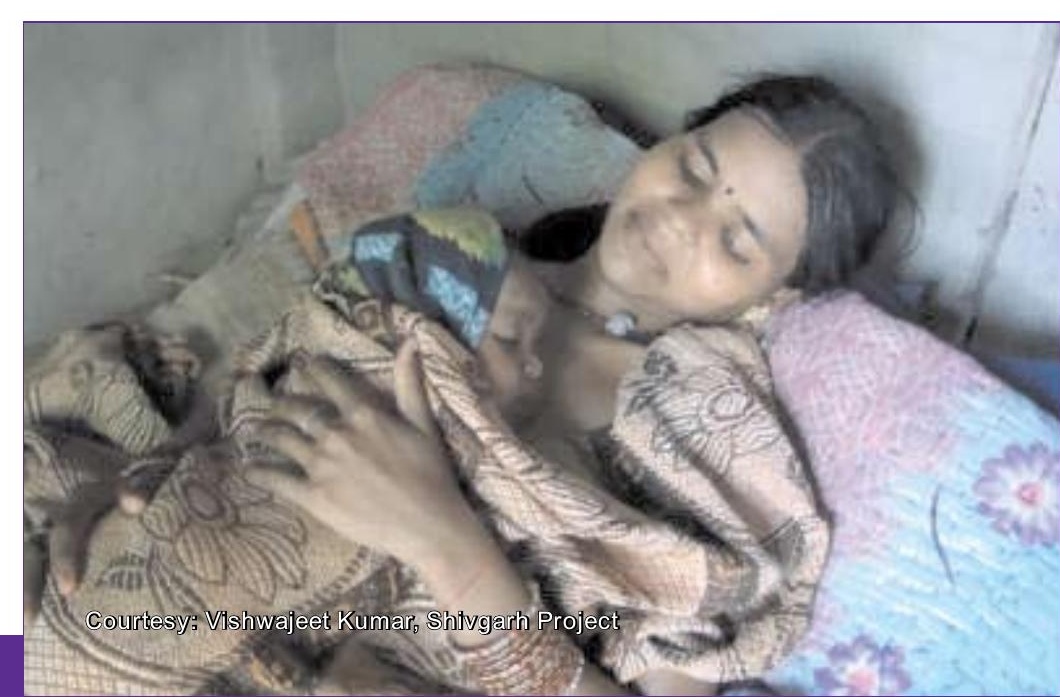


Willingness to practice STSC: Observations from in-depth interviews reveal that most women, if informed of the correct method of STSC, would be willing to adopt the practice with their next baby. For example, a woman said, "I am not aware of the kangaroo mother care method [kangaroo vidhil. I will do it if I am told about it. I would have no difficulty practicing kangaroo vidhi." Another woman said, "If I have more children then I will follow 'kangaroo vidhi'..." Women's willingness to adopt STSC is corroborated by the finding that two-thirds of women who were aware of STSC had indeed adopted the practice.

Moreover, in the context that most women and mothers-in-law believe that keeping the newborn warm is important, and had adopted various methods to keep the newborn warm, counseling efforts could effectively build on their willingness to promote the adoption of STSC.

\section{Implications for the BCC strategy}

Orientation of frontline health workers and community members on STSC: Currently knowledge of STSC within the community is negligible, and no more than one-third of frontline health workers are aware of STSC. From the communication perspective, it is necessary to build awareness among frontline workers, and through IPC, mid media and wherever possible, the mass media inform community members about the benefits of STSC and its correct practice. As women and families perceive the need to keep a newborn warm immediately after birth and adopt various methods for newborn thermal care, this perception could be reinforced by promoting STSC as a method to keep the baby warm. As the study reveals, with increase in knowledge of STSC, the likelihood of practicing of STSC is high.
Promote delay in bathing to keep the newborn warm: Changing the practice of immediate newborn bathing may be a challenge as the practice is embedded in cultural perceptions regarding the impurity of the unbathed newborn. Focused counseling efforts are needed during ANC visits and in the facility at the time of delivery to inform women and their families about the benefits of delaying the first bath.

The increase in institutional deliveries as a result of the Janani Suraksha Yojana provides a window of opportunity to promote the adoption of healthy newborn practices. PHC staff should be re-oriented and encouraged to counsel newly-delivered mothers, and accompanying family members, to delay newborn bathing and inform them how to practice STSC correctly. Pictorial presentations on the walls of the waiting area and/ or registration area in PHCs explaining the multiple benefits of delaying the first bath for the newborn as well as how to practice STSC could be effective in building awareness among both women and their family members.

Partnering with pundits: Study findings indicate that families depend on the pundit to select an auspicious date for newborn bathing. Advocacy with religious leaders to select an auspicious day for the ritual bathing of the newborn a week after birth could be an important strategy to promote thermal care.

\section{(2) Population Council}

Research that makes a difference

\section{Albt}

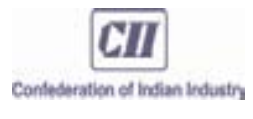

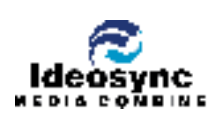
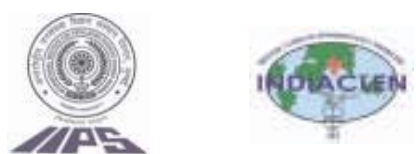

$\begin{array}{lll}\text { K } & B \\ \mathbf{s} & \mathbf{B} \\ \mathbf{W} & \mathbf{D} \\ \mathbf{A} & \mathbf{D} \\ \mathrm{M} & \mathbf{O} \\ \mathbf{Y} & \end{array}$

The opinions expressed in this publication do not necessarily reflect the views of the funding agencies.

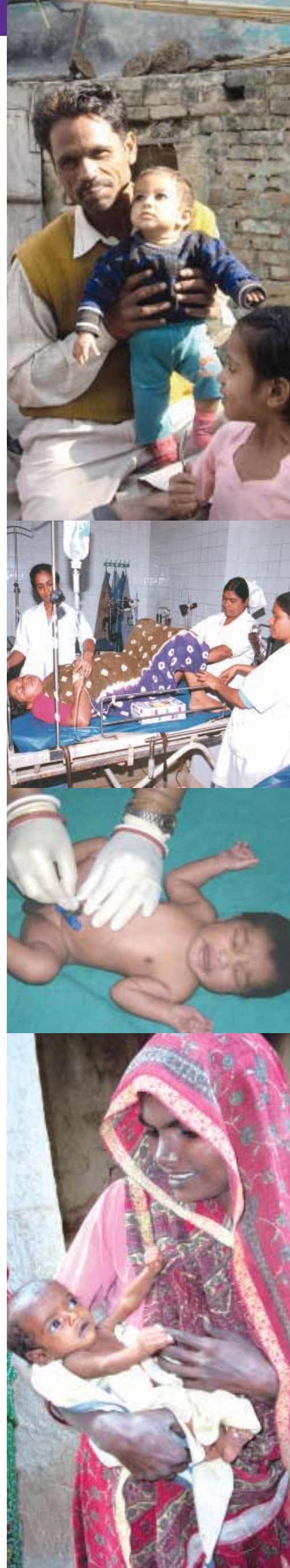

